\title{
DRIVERS AND GUIDELINES IN DESIGN FOR QUALIFICATION USING ADDITIVE MANUFACTURING IN SPACE APPLICATIONS
}

\author{
Dordlofva, Christo (1); Borgue, Olivia (2); Panarotto, Massimo (2); Isaksson, Ola (2) \\ 1: Luleå University of Technology; 2: Chalmers University of Technology
}

\begin{abstract}
In recent years, reducing cost and lead time in product development and qualification has become decisive to stay competitive in the space industry. Introducing Additive Manufacturing (AM) could potentially be beneficial from this perspective, but high demands on product reliability and lack of knowledge about AM processes make implementation challenging. Traditional approaches to qualification are too expensive if AM is to be used for critical applications in the near future. One alternative approach is to consider qualification as a design factor in the early phases of product development, potentially reducing cost and lead time for development and qualification as products are designed to be qualified. The presented study has identified factors that drive qualification activities in the space industry and these "qualification drivers" serve as a baseline for a set of proposed strategies for developing "Design for Qualification" guidelines for AM components. The explicit aim of these guidelines is to develop products that can be qualified, as well as appropriate qualification logics. The presented results provide a knowledge-base for the future development of such guidelines.
\end{abstract}

Keywords: New product development, Additive Manufacturing, Design for X (DfX), Design for Qualification, Space Applications

\section{Contact:}

Dordlofva, Christo

Luleå University of Technology

Business Administration, Technology and Social Sciences

Sweden

christo.dordlofva@ltu.se

Cite this article: Dordlofva, C., Borgue, O., Panarotto, M., Isaksson, O. (2019) 'Drivers and Guidelines in Design for Qualification Using Additive Manufacturing in Space Applications', in Proceedings of the 22nd International Conference on Engineering Design (ICED19), Delft, The Netherlands, 5-8 August 2019. DOI:10.1017/dsi.2019.77 


\section{INTRODUCTION}

The space industry is seeing an increase in demand for access to space to enable space-based services and human space flight, with new actors opting for market shares. This implies a need for a business-oriented evolution of technology and product development, decreasing cost and time to market. Space products traditionally involve a costly product development process for manufacturing low volumes (from one-off production to tens of parts per year) of high-performance products to be used in harsh environments. However, the space industry is currently in the middle of a transition due to the advent of the so called NewSpace companies such as SpaceX or Virgin Galactic (Salt, 2013). SpaceX, for instance, is planning to launch a constellation of more than 4000 low costs satellites to provide internet connection via space, and expect to have an operating network covering the US by 2020 (BBC News, 2018). This is one example of how cost and lead time reduction are becoming true drivers for space companies (Öhrwall Rönnbäck and Isaksson, 2018). In this context, additive manufacturing (AM) is a technology that has the potential to reduce lead-times and manufacturing costs (O'Brien, 2018). The use and development of AM is growing rapidly within the aerospace industry, but not without challenges since the whole product development process is impacted by the introduction of AM. One challenge of implementing AM in space applications is to demonstrate that products and processes meet specified quality and reliability requirements (Dordlofva and Törlind, 2017). The process dedicated to assuring that quality and reliability requirements are met is called qualification (Gerling et al., 2002). Previous studies (Dordlofva and Törlind, 2017) suggest that qualification aspects should be addressed already in the early phases of product development to ascertain that a product designed for AM can be qualified. However, the knowledge about the AM process chain is still low compared to traditional manufacturing processes (O'Brien, 2018). For this reason, it is difficult to predict the process outcome and consequently what to plan for in the qualification activities. The objective of this article is to provide a knowledge base for the creation of qualification guidelines to be utilised when designing products for a new manufacturing technology such as AM. Future research will utilise this knowledge to develop such guidelines, which would have the purpose of supporting the design of a product that can be qualified (Design for Qualification) and support the design of the qualification activities (the qualification logic). To guide this work, one research question was defined: How can qualification be considered in the early phases of product development of AM parts for space applications?

In the theoretical framework of this paper, product qualification is first presented in general terms to provide a context in which the challenge of design and qualification of AM products is discussed. The method used for data collection and analysis is then presented, where the interview study at two companies in the European space industry is described. The results and analysis of the interviews are thereafter presented following the same structure as in the theoretical framework by first providing the findings regarding product development and qualification in general, concluding on motivators for qualification activities in the space industry (qualification drivers). Thereafter the use of AM in space applications and the implications of the identified qualification drivers on designing and qualifying AM components are discussed. In this paper, AM is referring to metal Powder Bed Fusion (PBF) technologies, i.e. Electron Beam Melting (EBM) and Laser Beam Melting (LBM).

\section{PRODUCT QUALIFICATION}

Qualification can be defined as the activities performed to demonstrate that a product or a process meets or exceeds specified quality and reliability requirements (Gerling et al., 2002). In manufacturing process qualification, all the procedures that validate that a process meets specified performance and quality requirements are included. Process qualification assures that a process is controlled and produces repeatable qualified products (Tantra and van Heeren, 2013). Product qualification assesses the performance, quality and reliability of products under operational conditions and examines if the product meets the design requirements (Musgrave et al., 2009). Developing and qualifying a product and the processes for its manufacturing requires to comprehend how performance and reliability are related to product functionality and application (Gerling et al., 2002). Wang et al. (2008), state that three different types of qualification activities are performed during a product development process. First, virtual product qualification is implemented as means to evaluate the functionality and reliability of a product design without physical tests. Later, during physical product qualification, quality and reliability are evaluated based on tests on a qualification hardware. After virtual and physical product qualification, production begins and during the manufacturing, the product's quality is inspected and tested again. The authors consider this process as the 
third and final phase of the qualification activities, commonly referred to as quality assurance testing. The authors also propose that product design activities and qualification activities can include several feedback iterations. If the product design is found not to meet the qualification requirements, it is modified and qualified again before continuing with the next product development phase. For space components, qualification activities are performed on flight-like units at levels and in environments above the design requirements to ensure robustness and design margins (Musgrave et al., 2009). Flight-like units and qualification activities are however generally expensive for space systems (Öhrwall Rönnbäck and Isaksson, 2018) and for that reason, the iteration between product design activities and qualification activities proposed by Wang et al., is not necessarily applicable (Dordlofva and Törlind, 2017). These high costs of the qualification activities in the space industry are contradictory with the growing need of reducing cost. However, some authors such as Gerling et al. (2002) or Yadav et al. (2006) suggest that costs and lead time can be reduced if qualification activities are included earlier in the design process. Pecht (1993), Preussger et al. (2003) and Yadav et al. (2006) have proposed methodologies and guidelines for the electronics industry focusing on reliability assessment, test activities and test planning early in the development process. However, guidelines for approaching product design considering how the product should be qualified are missing. In product design, there are various design practices or supports that aim to maximise different aspects of a product. These are included in the Design for X (or Design for Excellence) methodology, where $\mathrm{X}$ represents product aspects such as functionality, manufacturability, safety, quality, or serviceability (Bralla, 1996). Designing a product to assure that it can be qualified should also be considered for products where qualification is an important part of the development (Pecht, 1993). Despite this, explicit Design for Qualification supports are lacking. DfX techniques provide three types of support: qualitative guidelines, metrics, and feasibility checks (Holt and Barnes, 2010). Metrics provide ways to measure a design's performance linked to the $\mathrm{X}$ aspects of the product that are sought for (e.g. cost or reliability), while feasibility checks aim at evaluating the $\mathrm{X}$ aspects linked to different life phases of the product (e.g. manufacture and assembly or end-o-life). Qualitative guidelines on the other hand are more generic, open for interpretation, and flexible, supporting the designers to e.g. understand what features and properties that should be included or avoided (ibid.). In this paper, Design for Qualification guidelines refer to this latter category.

\subsection{Design and qualification in additive manufacturing}

The use of AM in aerospace applications is increasing and major OEM:s continuously push the limit of the technologies. General Electric has for example developed and tested the Advanced Turboprop engine with 12 parts manufactured by AM (GE, 2017). However, information about the criticality level of parts that have been introduced in different applications is scarce (Gorelik, 2017), and within the space industry, secondary structures and other non-critical parts have been in focus (Brandão et al., 2017). This is due to that the qualification of AM processes and parts manufactured using AM remains a challenge (Frazier, 2014), and there is a lack of understanding of AM processes and standardised approaches to ascertain the quality of AM parts (Seifi et al., 2017). The need for AM standards has been acknowledged by the AM community and there are for example already nine published ISO standards and 25 under development (ISO/TC-261, 2019). However, the need for standardised procedures in industry is urgent, and for example NASA has expressed that they "cannot wait for national standard development organizations to issue AM standards", and have developed their own for space flight hardware (Clinton, 2018, p. 33). One of the complexities with AM that make standardisation challenging is that parts exhibit material characteristics such as anisotropic and location dependent properties, defects, and rough surfaces (Seifi et al., 2017). It has also been shown that part geometry can impact these material characteristics (ibid.), putting additional responsibility on design engineers to understand the capabilities of AM processes. Design for AM (DfAM) has received much attention with the increased interest for AM in industry and academia. The need to support engineers early in product development to allow them to explore the design potentials enabled by AM is often highlighted, and such DfAM methods have been proposed by e.g. Kumke et al. (2018) and Laverne et al. (2017). However, there is less focus on methods to explicitly support engineers in designing products that can be qualified. Holistic and relevant DfAM frameworks have been proposed by e.g. Kumke et al. (2016) and Zhu et al. (2017), where the importance of consideration for the whole manufacturing process capabilities (including pre and post $\mathrm{AM}$ ) are stressed. Explicit measures for dealing with the issue of process and product qualification early in the product development process are however lacking. O'Brien (2018) argues that at the current stage of AM maturity, sound DfAM for space applications should 
for example include considerations for part complexity, inspection and testing due to the intrinsic characteristics of AM parts.

\section{METHODOLOGY}

The data collection for this paper are semi-structured interviews carried out at two large companies that design and manufacture space components (Company A and Company B). Semi-structured interviews were preferred since the topic in study is complex and the concept of qualification can be interpreted in various ways, requiring lengthy explanations and follow up questions (Bryman and Bell, 2015). The companies were selected for the study since they both have a long history in the space industry delivering sub-system components to established international customers. The companies specialise in different components as presented in Table 1, which can reveal distinctive aspects of the qualification activities.

Table 1. Participating companies in the study.

\begin{tabular}{|c|l|c|}
\hline Company & Description & Employees \\
\hline A & $\begin{array}{l}\text { The company is developing complex and high-performance components for } \\
\text { aerospace. The studied part focuses on product development and } \\
\text { manufacturing of sub-system components for civil aircraft engines and } \\
\text { launcher applications. }\end{array}$ & 17000 \\
\hline B & $\begin{array}{l}\text { The company is operating within different segments of the aerospace } \\
\text { industry. The studied part is providing products for in-orbit applications and } \\
\text { the responsibility includes the whole chain from R\&D to sales for several } \\
\text { product areas. }\end{array}$ & 1400 \\
\hline
\end{tabular}

A total of 12 engineers were interviewed (eight at Company A, four at company B) with a range from 12 to 30 years of experience in the aerospace industry. The sampling of interviewees was done to have a mixture of different company roles; design engineers, method and material specialists, chief engineers, and department and division managers. It should be noted that Company A design and manufacture components for both civil aircraft and launcher applications, and that some of the interviewed engineers currently work with aircraft applications. All of the interviewees had experience from several phases of product development, and both companies are working towards the implementation of AM. Some of the interviewees had little experience of AM, and some had worked with AM for several years. All interviews were performed in Swedish and all quotes in this paper are consequently translated by the authors. The interviews were conducted by two of the authors, one of which have several years of experience in design of space systems and is situated as an industrial Ph.D. student at a company within the space industry. The other interviewing author is new to the space industry and was therefore able to take the role as an external auditor (Creswell, 2014).

The interviews lasted 40-60 minutes, and an interview guide was used with questions divided into two focus areas; Qualification in product development and Use of AM in space applications. In addition, questions about the interviewees background were included. After five initial interviews, the interview guide was revisited with a few questions reformulated to narrow down the focus on the most relevant aspects for the research question (Bryman and Bell, 2015). All but one of the interviews were recorded and transcribed (one of the interviewees wished not to be recorded, instead both authors took notes during the interview and then summarised it together). To clarify the empirical data and identify recurring and dominant themes, selective coding was used. Data reduction in the form of pattern matching and data displays was utilised to synthesise the findings (Miles and Huberman, 1994). The pattern matching involved the selection of eight categories based on topics identified before performing the interviews, with each category belonging to one of the two focus areas, and one category labelled 'Other'. The authors that performed the interviews individually read through each transcript and highlighted quotes related to these categories. The result from the coding was compiled in a spreadsheet that allowed comparison between the interviews. The quotes in the spread sheet were then condensed into a text document where similar quotes were grouped together. This text was then jointly read by the two interviewing authors. During this process, two of the eight initial categories were slightly reformulated to better fit the interviewees answers, and to include aspects from 'Other'. One new category was created within the focus area Use of AM in space applications. 


\section{RESULTS}

The outcome from the analysis are presented as follows. First, findings from the focus area Qualification in product development are presented, followed by a synthesis on how these findings can be used to account for qualification in the early phases of product development. Second, the findings from the focus area Use of AM in space applications are given, followed by a discussion on what the implications of these are on designing AM parts while considering qualification activities.

\subsection{How is qualification considered in product development?}

When asked if and how qualification is considered in the product development process, most of the interviewees answered that qualification plays an early role in product development since otherwise development and production would become very expensive as the amount of testing would increase significantly. Qualification plans are initiated early and are then developed along with the product. The assumptions that are made during product development with regard to manufacturing process outcome (e.g. material properties), what level of process control is possible in production, the available knowledge about the product or the manufacturing process (e.g. internal company legacy and external third-party standards), and the criticality of the product function were mentioned as aspects that impact a qualification logic. However, it was also noted that qualification is often not considered early enough. As one interviewee at Company A expressed it; "Today, qualification comes in when you start to converge towards a concept. Optimally, it should already come in when you have a set of product solutions". Similarly, one interviewee from Company B expressed that "it is seldom that we allow the work with qualification to impact the design work [...] rather, it is the design/product development that impacts what we need to qualify". Interviewees at Company B also mentioned that they try to re-use previous designs as much as possible since the amount of qualification that is needed for proven designs usually decrease. For this reason, it is also possible that the company increase the requirements on qualification for a certain product to make it more versatile and adaptable for future products. It was also stressed by one of the more senior engineers at Company A that there is not one way to do qualification; "for a new process [...] there is very little of ready recipes for how to qualify, without having a clear picture of what knowledge that has to be built. It is all very intimately connected. Often the word qualification is misused as a recipe that can be used". Another comment from a few interviewees at Company A was that system requirements are important considerations in product development. Understanding what customers and regulating bodies are expecting is essential. This also has the effect that qualification is something of "grey zone" in that the dialogue with the customer is important, where approaches to qualification can be suggested, and different customers can have different views of what is acceptable for showing compliance to specifications and regulations.

These results suggest that qualification is product and process dependent, since the assumptions made during product development and the requirements from the system the product will function in, influence the qualification logic. However, the qualification logic does not usually impact the design activities. Moreover, the qualification activities are not always tailored for one product but can include margins for similar products that might be developed in the future. A difference could be seen here between the companies since Company A usually have purposely designed products for a specific system with less possibility to reuse the same product in a new system. Qualification activities also depend on the customer's and third-party standards and regulations that must be followed. In this context, qualification is a challenging phase as there is no explicit "recipe" for how to qualify.

\subsubsection{Strategical and financial aspects of qualification}

Both companies rely on program funding together with their customers to be able to develop new products and technologies, hence relationships with customers are important for future business. This has been discussed in previous research as one characteristic of product development in the space industry (Lindwall et al., 2017). Since qualification is part of the product development, the cost of qualification is also financed by the customer. It became clear during the interviews that the market shift in the space industry has an impact on how product development is carried out at the two companies. As indicated by previous research (Öhrwall Rönnbäck and Isaksson, 2018), flexibility in design, cost-reduction, reduced time to market, and an increase in produced units (in production) were all aspects that were mentioned. As one interviewee said: "It's market competitiveness of course, it's all about being cheap and fast". From a qualification perspective some implications of this change were given: 
- More responsibility for the design and qualification is pushed on to the design organisation, i.e. subsystem component suppliers such as Company A and B (mentioned by Company A and B).

- To reduce cost, the pressure has increased to use less number of manufactured components that go through the process of qualification, and consequently also to consider what needs to be qualified through testing (Company A).

- The demand for an increase in produced units in production means that cheaper components must be used to be competitive. However, these are less reliable and more difficult to qualify according to traditional qualification requirements (Company B).

The interviews indicate that cost and time-to-market reduction are primordial to assure market competitiveness, where company profit is a factor to consider. The pressure for increasing production volumes may need to decrease the requirements on product reliability if cost, time-to-market and profit goals shall be feasible as companies try to reduce their qualification efforts. A well-established knowledge base for the creation of qualification guidelines would support engineers to design adequate qualification activities for either low or large production volumes. Moreover, the early implementation of qualification guidelines in the design process could reduce the cost of qualification activities as products are designed for qualification.

\subsection{Qualification drivers for product development in space applications}

Synthesising the results presented above, a number of motivators for qualification activities in space industry were deduced. These motivators are labelled qualification drivers since they drive the requirements set on the product qualification, and the decisions behind the establishment of a qualification logic. Figure 1 presents a diagram where the identified qualification drivers are shown along with how they are linked to the product development, the product qualification, and the creation of Design for Qualification guidelines.

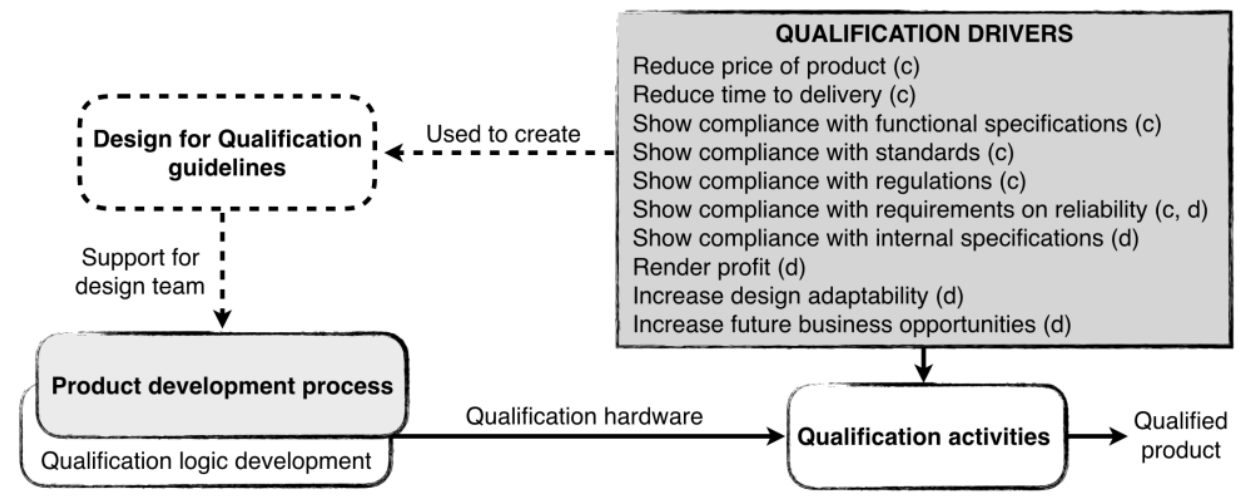

Figure 1. Identified qualification drivers for product development in space applications ( $c=d r i v e r$ for customer satisfaction, $d=d r i v e r$ for design organisation satisfaction).

From the perspective of the companies there are two stakeholders in the development and qualification of a product. The customer that finances and/or purchases the product, and the companies themselves that design and manufacture the product, i.e. the design organisation. The qualification drivers are related with the satisfaction of either customer ('c' in Figure 1), or design organisation ('d' in Figure 1). To achieve customer satisfaction, qualification activities must aim to:

- Reduce overall product price and time to delivery: “(..) it's all about being cheap and fast”.

- Show compliance with product functional and technical specifications: the product must perform the functions required by the customer.

- Show compliance with general standards and regulations: Standards are usually third-party and regulations can be either from a governing body (e.g. ECSS from ESA) or specifications from a customer.

- Show compliance with requirements on reliability: Different customers are willing to accept different amounts of risks. It was specifically mentioned that NewSpace companies are willing to accept a higher risk than traditional space companies. 
To achieve design organisation satisfaction, qualification activities must aim to:

- Show compliance to requirements on reliability: While some customers were mentioned to accept a higher risk, this was also said to impose an increased responsibility on the design organisation to be liable for failures, implying decisions on risk acceptance.

- Show compliance with internal specifications: Design organisations with internal specifications can impose more stringent requirements than e.g. general standards.

- Render company profit: Product development has to render profitable business cases.

- Increase adaptability of product designs for future business opportunities: design organisations can increase the requirements on qualification for a certain product to make it versatile and adaptable for future products.

The qualification activities and the accomplishment of the above-mentioned objectives for customer and design organisation satisfaction are highly dependent of the capabilities of the design organisation to develop and manufacture products. For that reason, company capabilities (and capabilities of any suppliers used) have to be considered in product design and qualification logic development as well. These capabilities include aspects such as the activities that can be performed as part of the qualification processes (e.g. inspection) or the manufacturing technologies that are available to the company. These capabilities are related with company experience and knowledge (Dordlofva and Törlind, 2017).

\subsection{Challenges and expectations on qualification of additive manufacturing}

Comparing the stated reasons why the companies are exploring AM, a difference could be seen in that Company A put more emphasis on the importance of cost reduction. Within Company B, the possibility to come up with new and unique design solutions was explicitly said to be more alluring than reducing cost. However, interviewees from both companies mentioned that there is no pressure from customers to introduce AM. Instead, they expressed that convincing customers to use AM products, and to finance such product development, is a challenge. Two other challenges for AM qualification mentioned by almost all of the interviewees were variation in AM process outcome (i.e. material properties) and lack of knowledge about AM processes. With regard to process outcome, there was a belief among the mechanical and material engineers working with AM that nominal mechanical properties related to strength will not be as much of an issue compared to life related mechanical properties (fatigue and damage tolerance) and the variation that can be seen in material characteristics affecting these properties (e.g. surface roughness and defects). From this perspective, one interviewee from Company A expressed a concern for the increased design freedom that comes with AM: "You can for example make surfaces in a way that you utilise the material to its maximum with increased average stress in the material [...] since you optimise your [part] structure. And the two together become a dangerous combination [referring to material defects]". The need to challenge conventional interfaces of components to fully utilise the potential with AM, i.e. to think AM on a system-level, was brought up by a few interviewees. To challenge conventional interfaces could however be difficult since it would imply that e.g. a customer and a component supplier might intrude on traditional responsibilities. It could however also expand the product portfolio and give a better understanding of the system requirements.

Insights into the expectations on AM qualification were also given during the interviews. Building process understanding is the key to be able to show a solid background knowledge for convincing customers that the chosen qualification logic is safe and secure. Therefore, in the near term, it is expected that using established knowledge from traditional manufacturing processes will be necessary, using a conservative approach to AM materials based on testing and analytical verification with safety factors. For life sensitive parts, designing for crack propagation will probably be necessary as opposed to crack initiation (fatigue). For example, this could lead to thicker walls to account for the worst case with regard to e.g. defects. It is foreseen that customers will be very cautious and not willing to bend current qualification requirements for metal materials. As with traditional manufacturing processes, AM processes are expected to be frozen on a set of parameters identified during development and testing. When some of the senior engineers at Company A were asked whether it could be acceptable to have a more expensive qualification of AM parts, they believed that this could be the case for early products in order to learn about the processes and start the discussions on qualification. However, in the long term, using AM has to be a competitive business case, hence decreasing the amount of testing used for each product. There will probably not be one qualification logic that can be used for any AM part, but it will be dependent on product and process. However, there could be process specific requirements on e.g. the number of test specimens that have to be printed with the part. 
The interviews indicate that while the companies strive to introduce AM to decrease cost and find new competitive design solutions, their customers are conservative and prefer to use 'what is known' while reducing price. Design for Qualification guidelines should assist companies to give attention to critical areas or features of a product to find design solutions that balance the utilisation of layered manufacturing with the available knowledge of AM process capabilities. For example, topology optimisation is often highlighted as one of the main benefits of AM, but as indicated in the interviews, stress optimisation could for example impose an increased risk of failure for life-limited parts due to rough surfaces and defects. Hence, the assumptions that need to be made during design with regard to material properties, design margins, impact of print direction, testing and inspection etc., should be acknowledged in such guidelines. The importance for a company to introduce AM in a specific product should be assessed to set the acceptance of risk and of cost for qualification and production, especially in the near term when building knowledge about AM processes is crucial.

\subsection{Strategies to develop AM qualification guidelines for space applications}

The qualification drivers presented in Figure 1 gives an overview of the relevant aspects to be considered in qualification of products for space applications. Relating these with challenges and expectations on AM qualification, strategies for creating Design for Qualification guidelines are proposed in Table 2.

Table 2. Strategies for the development of Design for Qualification guidelines for AM parts.

\begin{tabular}{|c|c|c|}
\hline $\begin{array}{c}\text { Qualification drivers } \\
\text { related to customer } \\
\text { satisfaction }\end{array}$ & $\begin{array}{c}\text { Qualification drivers } \\
\text { related to design } \\
\text { organisation satisfaction }\end{array}$ & $\begin{array}{l}\text { Strategies for Design for Qualification } \\
\text { guidelines with regard to the design of } \\
\text { qualification logic (L) and product (P) }\end{array}$ \\
\hline $\begin{array}{l}\text { Reduce price and time- } \\
\text { to-delivery }\end{array}$ & Render profit & $\begin{array}{l}\text { Define accepted cost of qualification (L) } \\
\text { Reduce the number of hardware to test }(\mathrm{L}) \\
\text { Consider reusing previous designs (L, P) } \\
\text { Assess suitability of using AM (P) } \\
\text { (may depend on system-design) }\end{array}$ \\
\hline $\begin{array}{l}\text { Show compliance with } \\
\text { product functional and } \\
\text { technical specifications }\end{array}$ & & $\begin{array}{l}\text { Assess product criticality }(\mathrm{L}, \mathrm{P}) \text { : } \\
\text { System-level requirements } \\
\text { Product requirements }\end{array}$ \\
\hline $\begin{array}{l}\text { Show compliance with } \\
\text { standards, regulations, } \\
\text { and customer } \\
\text { specifications }\end{array}$ & $\begin{array}{l}\text { Show compliance with } \\
\text { internal specifications }\end{array}$ & $\begin{array}{l}\quad \text { AM process maturity and knowledge } \\
\text { Define applicable AM standards (L, P) } \\
\text { Define applicable AM specifications (L, P) } \\
\text { Define applicable regulations (L) } \\
\text { Assess impact of production volume (L) }\end{array}$ \\
\hline \multicolumn{2}{|c|}{ Show compliance to reliability requirements } & $\begin{array}{l}\text { Assess accepted level of risk from customer } \\
\text { and design organisation }(\mathrm{L}, \mathrm{P})\end{array}$ \\
\hline & $\begin{array}{l}\text { Increase future business } \\
\text { opportunities and } \\
\text { adaptability }\end{array}$ & $\begin{array}{l}\text { Evaluate possibilities and need for adaptability } \\
\text { to: } \\
\text { Adapt design margins }(\mathrm{P}) \\
\text { Adapt qualification requirements }(\mathrm{L}) \\
\end{array}$ \\
\hline & $\begin{array}{l}\text { Comply with } \\
\text { manufacturing capabilities: } \\
\text { AM process } \\
\text { Post-processing } \\
\text { Inspection methods } \\
\text { Test methods }\end{array}$ & $\begin{array}{l}\text { Define approved AM processes (P) } \\
\text { Assess capabilities to design for: (L, P) } \\
\text { AM (best practices) } \\
\text { Post-processing } \\
\text { Inspection } \\
\text { Assess the use of test artefacts (L, P) } \\
\text { Assess proven qualification logics (L) }\end{array}$ \\
\hline
\end{tabular}

These proposed strategies should aid design organisations in the space industry to develop qualification guidelines to approach product development for AM in a manner that can render products that can be qualified. By developing and implementing Design for Qualification guidelines, planning of qualification activities should be given attention during early product design activities. The strategies stress the need to clarify the current level of AM knowledge within the design organisation (and in general standards), include customer dialogue in the design process to agree on acceptable price and risks, assess the specific product application and the implication of using AM (also on a system-level), define what testing and 
inspections method that can be used, and what implications there are on future business opportunities. This way, the strategies should facilitate the development of a qualification logic that is suitable for the product, the AM process, the company capabilities, and the customer expectations. It is also considered that by using guidelines as support for Design for Qualification, there is flexibility in their application depending on the product, where for example "adaptability" might not be relevant for specific products purposely designed for one system.

\section{CONCLUSION}

AM has been introduced in the space industry to evaluate its potential to find new competitive design solutions and to decrease cost and lead-time in development and manufacturing. However, there is a need to increase the knowledge about AM process capabilities and AM products to show a solid qualification logic to convince customers that the product function can be guaranteed. Qualification is an integral, but expensive, part of product development in the space industry, and to mitigate time-consuming and costly qualifications activities, the qualification logic should be included as a factor early in the design process. This meaning that, since established qualification approaches for AM parts are still missing (Seifi et al., 2017), products should be designed to facilitate an affordable qualification. This paper proposes to assess what knowledge and processes that are available within an organisation to help define a qualification logic that is suitable for the organisation's capabilities. For example, local oversizing might be necessary to account for defects since using traditional design approaches based on established defect densities from material testing and manufacturing process control is too expensive (Frazier, 2014). Unless the qualification strategy is defined when design decisions are made, the cost of qualification might become too large. This implies that qualification strategies need to be established in the early phases of product development, preferably already in the conceptual phase.

In this paper, strategies for the creation of guidelines that should support engineers in the development of qualification strategies for AM space components are presented. For supporting the process of designing parts that can be qualified, several motivators that have an impact on the qualification activities for AM in space applications have been identified. These motivators are labelled qualification drivers and serve as a knowledge base for creating guidelines to support the development of a qualification logic, and to support Design for Qualification. The study is limited to 12 interviews at two companies within the space industry. Due to this sample limitation the identified qualification drivers should be considered in the context of AM space components and other applications should be further studied. Future research will focus on the development of Design for Qualification guidelines that can be applied in product development of AM products. Future work is also to develop modelling support to complement the guidelines for AM products and to support the associated qualification process.

\section{REFERENCES}

BBC News. (2018), “SpaceX launches broadband pathfinders”, available at: http://www.bbc.co.uk/news/scienceenvironment-43160073 (accessed 2 December 2018).

Bralla, J.G. (1996), Design for Excellence, 1st ed., McGraw-Hill/Knovel - online version.

Brandão, A.D., Gerard, R., Gumpinger, J., Beretta, S., Makaya, A., Pambaguian, L. and Ghidini, T. (2017), "Challenges in Additive Manufacturing of Space Parts : Powder Feedstock Cross-Contamination and Its Impact on End Products", Materials, Vol. 10 No. 5. https://doi.org/10.3390/ma10050522

Bryman, A. and Bell, E. (2015), Business Research Methods, 4th ed., Oxford University Press, Oxford, UK.

Clinton, R.G. (2018), "Overview of Additive Manufacturing Initiatives at NASA Marshall Space Flight Center”, (Presentation), available at: https://ntrs.nasa.gov/archive/nasa/casi.ntrs.nasa.gov/20180001514.pdf (accessed 17 March 2019).

Creswell, J.W. (2014), Research Design: Qualitative, Quantitative, and Mixed Methods Approaches, 4th ed., Sage Publications, Thousand Oaks, CA.

Dordlofva, C. and Törlind, P. (2017), "Qualification Challenges with Additive Manufacturing in Space Applications", Proceedings of the 28th Annual International Solid Freeform Fabrication Symposium, Austin, TX, USA, August 2017, pp. 2699-2712.

Frazier, W.E. (2014), "Metal Additive Manufacturing: A Review", Journal of Materials Engineering and Performance, Vol. 23 No. 6, pp. 1917-1928. https://doi.org/10.1007/s11665-014-0958-z

GE. (2017), "GE Aviation announces 1st run of the Advanced Turboprop engine", available at: https://www.geaviation.com/press-release/business-general-aviation/ge-aviation-announces-first-run-advancedturboprop-engine (accessed 15 March 2019). 
Gerling, W.H., Preussger, A. and Wulfert, F.W. (2002), "Reliability qualification of semiconductor devices based on physics-of-failure and risk and opportunity assessment", Quality and Reliability Engineering International, Vol. 18 No. 2, pp. 81-98. https://doi.org/10.1002/qre.468

Gorelik, M. (2017), "Additive manufacturing in the context of structural integrity", International Journal of Fatigue, Vol. 94, pp. 168-177. https://doi.org/10.1016/j.ijfatigue.2016.07.005

Holt, R. and Barnes, C. (2010), "Towards an integrated approach to 'Design for X': an agenda for decision-based DFX research”, Research in Engineering Design, Vol. 21 No. 2, pp. 123-136. https://doi.org/10.1007/s00163-0090081-6

ISO/TC-261. (2019), “ISO/TC 261 Technical Committee”, available at: https://www.iso.org/committee/629086.html (accessed 15 March 2019).

Kumke, M., Watschke, H., Hartogh, P., Bavendiek, A.K. and Vietor, T. (2018), "Methods and tools for identifying and leveraging additive manufacturing design potentials", International Journal on Interactive Design and Manufacturing, Springer, Paris, Vol. 12, pp. 481-493. https://doi.org/10.1007/s12008-017-0399-7

Kumke, M., Watschke, H. and Vietor, T. (2016), “A new methodological framework for design for additive manufacturing", Virtual and Physical Prototyping, Vol. 11 No. 1, pp. 3-19. https://doi.org/10.1080/17452759.2016.1139377

Laverne, F., Segonds, F., D’Antonio, G. and Le Coq, M. (2017), "Enriching design with X through tailored additive manufacturing knowledge: a methodological proposal”, International Journal on Interactive Design and Manufacturing, Springer, Paris, Vol. 11, pp. 279-288. https://doi.org/10.1007/s12008-016-0314-7

Lindwall, A., Dordlofva, C. and Öhrwall Rönnbäck, A. (2017), "Additive manufacturing and the product development process: Insights from the space industry”, Proceedings of the International Conference on Engineering Design, ICED17.

Miles, M.B. and Huberman, A.M. (1994), Qualitative Data Analysis: An Expanded Sourcebook, Sage Publications, Beverly Hills, CA.

Musgrave, G.E., Larsen, A.M. and Sgobba, T. (Eds.). (2009), Safety Design for Space Systems, ButterworthHeinemann.

O’Brien, M.J. (2018), “Development and qualification of additively manufactured parts for space”, in Helvajian, H., Piqué, A. and Gu, B. (Eds.), Proceedings of SPIE, Laser 3D Manufacturing V, SPIE, pp. 1-14. https://doi.org/10.1117/12.2297204

Öhrwall Rönnbäck, A.B. and Isaksson, O. (2018), "Product Development Challenges for Space Sub-System Manufacturers", Proceedings of the 15th International Design Conference, pp. 1937-1944. https://doi.org/10.21278/idc.2018.0534

Pecht, M.G. (1993), "Design for Qualification”, Proceedings of Annual Reliability and Maintainability Symposium, pp. $1-4$.

Preussger, A., Kanert, W. and Gerling, W. (2003), "Reliability qualification of a smart power technology for high temperature application based on physics-of-failure and risk \& and opportunity assessment", 2003 IEEE International Reliability Physics Symposium Proceedings., pp. 378-384. https://doi.org/10.1109/RELPHY.2003.1197777

Salt, D. (2013), "NewSpace - delivering on the dream”, Acta Astronautica, Elsevier, Vol. 92 No. 2, pp. $178-186$. https://doi.org/10.1016/j.actaastro.2012.08.020

Seifi, M., Gorelik, M., Waller, J., Hrabe, N., Shamsaei, N., Daniewicz, S. and Lewandowski, J.J. (2017), "Progress Towards Metal Additive Manufacturing Standardization to Support Qualification and Certification", JOM, Vol. 69 No. 3, pp. 439-455. https://doi.org/10.1007/s11837-017-2265-2

Tantra, R. and van Heeren, H. (2013), "Product qualification: a barrier to point-of-care microfluidic-based diagnostics?”, Lab on a Chip, Vol. 13 No. 12, pp. 2199-2201. https://doi.org/10.1039/c31c50246e

Wang, W., Azarian, M.H. and Pecht, M. (2008), "Qualification for product development”, 2008 International Conference on Electronic Packaging Technology \& High Density Packaging, IEEE, pp. 1-12. https://doi.org/10.1109/ICEPT.2008.4606933

Yadav, O.P., Singh, N. and Goel, P.S. (2006), "Reliability demonstration test planning: A three dimensional consideration”, Reliability Engineering \& System Safety, Vol. 91 No. 8, pp. 882-893. https://doi.org/10.1016/j.ress.2005.09.001

Zhu, Z., Pradel, P., Bibb, R. and Moultrie, J. (2017), “A Framework for Designing End Use Products for Direct Manufacturing Using Additive Manufacturing Technologies", Proceedings of the 21 st International Conference on Engineering Design (ICED17), Vol. 5, pp. 327-336.

\section{ACKNOWLEDGEMENTS}

The authors acknowledge the financial support from LTU Graduate School of Space Technology, the area of advance Production at Chalmers, the EU project RIT (Space for Innovation and Growth), and the Swedish National Space Agency through NRFP (Swedish National Space Research Programme). 